\title{
MERCADO Futuro: LIMITAÇÕES E VANTAGENS PARA O EMPRESÁRIO RURAL
}

Viviane Santos Pereira

Administradora e Mestranda em Administracão - Dinâmica e Gestão de Cadeias Produtivas Universidade Federal de Lavras - UFLA/DAE. E-mail:vivsantosp@yahoo.com.br

Ana Adalgisa Simão

Administradora e Mestranda em Administração

- Gestão Social, Ambientee Desenvolvimento Universidade Federal de Lavras - UFLA/DAE.

\section{RESUMO}

ABSTRACT

Nas diversas cadeias que compõem o agribusiness, destacamse, em importância econômica, as relações entre o empresário rural e a agroindústria e os agentes que afetam e coordenam os fluxos dos produtos, entre os quais estão as bolsas de futuros. $\mathrm{O}$ mercado futuro é um instrumento eficiente e moderno de comercialização agrícola utilizado em larga escala nas economias desenvolvidas. Este estudo tem como objetivo analisar as dificuldades e benefícios de investidores, principalmente o empresário rural, para negociar no mercado futuro agrícola. Uma de suas vantagens é permitir ao empresário rural planejar sua atividade fazendo orçamentos com controle dos custos. A vantagens que o mercado futuro oferece para quem opera vão muito além da simples proteção do preço. Negociando nos prazos estipulados, o investidor no mercado futuro pode sair a qualquer momento da sua posição, antes do vencimento do contrato, recomprando suas posições e dias depois voltando a vender. A principal limitação percebida com o mercado futuro agropecuário é a de ter que pagar os ajustes diários (variações de preços desfavoráveis exigidos pela BM\&F e os custos operacionais que muitas vezes levam o hedger a desistir da operação).

Palavras-chave: mercado futuro, empresário rural, vantagens, limitações, oportunidades.

\begin{abstract}
Among the several chains that compose agribusiness, are distinguished, in economic importance, the relations between the agricultural entrepreneur and the agro-industry and the agents who affect and coordinate the flows of the products, among which the stock markets of futures are. The futures market is an efficient and modern tool used in wide scale in agricultural commercialization in the developed economies. The goal of this study is to analyze the difficulties and benefits of investors, mainly the agricultural entrepreneur, as they make businesses in the agricultural futures market. One of its advantages is to allow the agricultural entrepreneur to plan his activity by making budgets with cost control. The advantages that the futures market offers to those who operate in it go well beyond the simple protection of the price. Negotiating in the stipulated periods, the investor in the futures market can leave bis position at any time, before the expiration of the contract, repurchasing his positions and selling them again days later. The main limitation perceived regarding the farming futures market is to have to pay the daily adjustments (variations of favorable prices demanded by the $B M \& F$ and the operational costs that many times make bedger give up the operation).
\end{abstract}

Word-key: futures market, agricultural entrepreneur, advantages, limitations, oprotunidades. 


\section{INTRODUÇÃO}

O fenômeno da globalização dos mercados vem imprimindo, de forma acelerada, uma nova dinâmica ao agribusiness brasileiro. Nas diversas cadeias agroindustriais é nítida e constante as estratégias de integração em vários níveis, a aquisição, a venda e compra entre empresas. Tais iniciativas visam conquistar as novas oportunidades de negócios no mercado doméstico e internacional, tendo o consumidor urbano como principal sinalizador dos diversos arranjos destes segmentos no que diz respeito a inovação, difusão, mudanças, preços e demanda derivada por produtos de origem rural (SOUZA 1994).

Souza (1994) comenta que é a partir desta abordagem sistêmica, através de esquemas matriciais das cadeias agroindustriais dentro do agribusiness, que são montados gigantescos complexos logísticos, onde aparecem integradas as funções de produção, processamento, transporte, finanças, bolsas de mercadorias e de futuros e políticas governamentais.

Dentro das diversas cadeias que compõem o agribusiness destacam-se, em importância econômica, as relações entre o empresário rural e a agroindústria e os agentes que afetam e coordenam os fluxos dos produtos, entre os quais estão as bolsas de futuros e o governo.

O mercado futuro é um instrumento eficiente e moderno de comercialização agrícola utilizado em larga escala nas economias desenvolvidas. Estendendo sua ação além das commodities agrícolas, a importância desse serviço e conseqüente beneficio para a sociedade é equiparada à introdução da moeda nas relações de troca. Trata-se de um mercado que evoluiu paulatinamente das formas tradicionais de comercialização para uma atividade poderosa, pois movimenta, em nível mundial, bilhões de dólares anuais; empregando centenas de milhares de pessoas.

Este estudo tem como objetivo analisar as dificuldades e beneficios de investidores, principalmente o empresário rural, para negociar no mercado futuro agropecuário.

\section{O MERCADO FUTURO}

Mercado futuro são aqueles que propiciam a negociação de contratos, nos quais, compradores e vendedores, definem acordos de realização de negócios futuros de produtos específicos a preços estabelecidos.

No mercado futuro é possível comprar sem ter dinheiro e vender sem ter mercadoria e em que menos de $2 \%$ das operações são liquidadas pela entrega efetiva do bem transacionado. O objetivo é fixar o preço de um negócio hoje, fechar um contrato com base nas expectativas de mercado e liquidá-lo no futuro, com ou sem a entrega física dos bens transacionados. Este é o princípio dos mercados futuros (NASCIMENTO 1998).

Os principais agentes envolvidos nas transações do mercado futuro são os vendedores, especuladores, compradores e corretoras e operadoras. Os vendedores (cooperativas e produtores rurais) possuem a mercadoria física e buscam neste mercado garantia de venda do produto no preço e data desejado. Os compradores (exportadoras, torrefadoras, etc.) são os interessados em comprar merćadoria para uma data futura procurando garantia de aquisição do produto no preço e data desejado. Os especuladores são aqueles interessados apenas nas transações de compra e venda de mercadoria, visando obter lucro nas oscilações dos preços, porém sem interesse em comprar ou vender efetivamente o produto físico. As corretoras e operadores são o elo de ligação entre os hedgers, que são os compradores e vendedores, para que sejam efetuadas suas negociações.

Para o vendedor a operação a futuro tende a necessidade de fixar um preço de venda de sua mercadoria antecipadamente, para se protejer do risco de queda no preço e garantir uma margem de rentabilidade.

Para um comprador, o negócio a futuro tende a necessidade de assegurar o preço de seu insumo antecipadamente de modo a ter um custo compatível com uma determinada margem de rentabilidade, protegendo-se do risco de uma alta nos preços dos mesmos.

Nascimento (1998) comenta que os mercados futuros devem ser entendidos de maneira integrada ao mercado físico, pois fazem parte de um processo que engloba a produção, processamento, comercialização, consumo e financiamento desse processo. A bolsa é uma instituição que desempenha o papel de conector entre aquelas partes do processo de produção, comercialização e financiamento, de forma a expressar e sinalizar através do processo a força de mercado. A bolsa não é portanto, o local onde os preços se formam, mas um local onde os preços se manifestam. O pregão é um local onde se reúnem os representantes das sociedades corretoras para executar as ordens de compra ou venda das partes.

As partes realizam um contrato de compra e venda, com as especificações da quantidade e qualidade da mercadoria e com o prazo para vencimento estipulado.

Os preços são formados a partir da expectativa do preço em um tempo futuro. São negociados na BM\&F contratos futuros de moeda, índices, taxas, ouro e produtos agropecuários. De acordo com Souza (1994), a Bolsa de Mercadorias \& Futuros (BM\&F) é uma instituição de mercado que tem entre suas diversas finalidades, apregoamento de preços do mercado a vigorarem no futuro, através da negociação de contratos representativos de commodities, com preços pré-fixados em datas de vencimentos futuros.

A partir de 1988, os mercados futuros de ativos financeiros obtiveram um aumento razoável, sinalizando crescimento contínuo, com alguns contratos futuros alcançando porte mundial, tais como os indices de ações IBOVESPA, o ouro e taxas de juros. No caso particular das commodities agrícolas, o mercado é muito insignificante quando comparado com a magnitude e a capacidade do setor agropecuário brasileiro (SOUZA 1994).

A bolsa de futuros faz a classificação dos produtos para assegurar que os produtos estejam de acordo com os contratos realizados. É também encarregada de supervisionar os pregões, divulgar os dados estatísticos relacionados às operações ocorridas, as cotações e administrar os processos de liquidação financeira e entrega das mercadorias. 


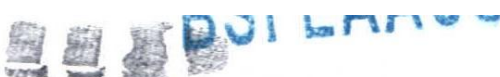

O mercado futuro de produtos agropecuários é muito forte no Brasil, pois a BM\&F figura entre as maiores bolsas de futuros e negociação destes produtos, em todo o mundo. Isto se deve não apenas pelas grandes dimensões da produção agropecuária brasileira, mas também pela confiança e a estrutura sólida disponibiliza da todos os investidores.

\section{MERCADO FUTURO AGROPECUÁRIO}

A administração do problema de risco na comercialização agrícola surgiu no século XIX. Crescimento monumental da industrialização e do mercado americano originaram maiores necessidades de capital e de créditos, e também riscos crescentes de preços, devido basicamente, aumento de competição entre produtores e os agentes de comercialização. A necessidade de capital de giro foi realizada pelos sistemas bancários nacionais e internacionais; a necessidade de capitais destinados ao novo tipo de produção foi atendida pelas bolsas de valores. Para que os riscos de preços fossem transferidos, alguém deveria estar disposto a assumi-los. Surgem então as bolsas de futuros com estes propósitos (TSUNECHIRO, 1983).

A lógica econômica dos mercados futuros é permitir que produtores, indústrias, comerciantes, exportadores e importadores negociem - com preço qualidade e quantidades conhecidas - contratos de mercadorias que serão necessárias num determinado prazo. Permitir que seja possível fazer um seguro diminuindo os riscos ocasionados pela oscilação dos preços. Atrair para esse mercado grande número de detentores de capital por acreditarem poder obter bons lucros com as oscilações de preços, estão dispostos a absorver esses risco que o setor produtivo precisa evitar dando maior liquidez ao mercado.

Para Castro (2001), no Brasil, considerando o fato do país ser um dos maiores produtores de commodities do mundo (Quadro 1), a indústria de derivativos agrícolas ainda é pouco expressiva quando comparada, por exemplo, a dos EUA, contudo, essa vem se desenvolvendo gradativamente ao longo dos anos. Este crescimento foi e está sendo promovido, principalmente, por reestruturações nas relações contratuais e nos padrões interno de negociação, além da constante disseminação da cultura de mercados de derivativos através de cursos, seminários, e palestras ministrados por técnicos da BM\&F, professores universitários, entre outros.
De acordo com Souza e Andrade (1986), a agropecuária apresenta mais peculiaridades em relação a outros setores da economia, destacando-se as seguintes: a terra como fator de produção, o tempo de produção maior que o tempo de trabalho, a irreversibilidade do ciclo de produção, o ciclo de produção dependente de condições biológicas e dependência do clima. Tais peculiaridades provocam sazonalidade da produção e dos riscos físicos e de preços inerentes à atividade, caracterizando o setor agrícola por altas oscilações na produção e nos seus preços. Isto acaba transmitindo ao setor baixos retornos e giro operacional lento.

Por isso, o setor agropecuário é caracterizado por apresentar instabilidade de preços, e de renda em nível mais elevado que os demais. $\mathrm{O}$ empresário rural enfrenta condições de risco e de incerteza de forma que suas decisões muitas vezes levam por extensão à instabilidade do abastecimento e dos preços ao consumidor.

comportamento dos mercados futuros é estudado intensivamente nos países desenvolvidos e principalmente nos Estados Unidos. Os trabalhos mais significativos desta vasta literatura concentram-se em discussões dos preços e alocação temporal de estoques de mercadorias. Outros problemas, intimamente associados aos primeiros, que têm merecido a atenção dos pesquisadores é o comportamento do bedger e do especulador(TSUNECHIRO, 1983).

\subsection{Hedgers e especuladores}

No mercado futuro existem dois agentes econômicos fundamentais: hedger, aquele interessado em se proteger das oscilações de preço de mercado e o especulador, aquele interessado em obter ganhos financeiros com o mercado futuro.

$O$ bedger pode ser definido como uma operação de seguro de risco. A especulação é uma operação em que o agente econômico não está interessado no produto físico, mas apenas em obter ganhos financeiros com a compra e venda nos mercados futuros, realizando ganhos ou perdas diariamente sempre visando ao lucro.

A principal importância do especulador é propiciar liquidez ao mercado ou seja, comprar quando houver um hedger em vender ou vender quando houver um bedger interessado em comprar.

Melo (1978) comenta que uma das mais importantes fun-
Quadro 1: Posição do Brasil em termos de produção e exportação mundial de commodities agrícolas, 1998.

\begin{tabular}{|l|c|c|}
\hline Commoditiy & Produção/Posição & Exportação/Posição \\
\hline Café* & $35.800\left(1^{\circ}\right.$ lugar $)$ & $23.300\left(1^{\circ}\right.$ lugar $)$ \\
\hline Boi gordo** & $6.140\left(3^{\circ}\right.$ lugar $)$ & $335\left(6^{\circ}\right.$ lugar $)$ \\
\hline Soja*** & $29.500\left(2^{\circ}\right.$ lugar $)$ & $8.400\left(2^{\circ}\right.$ lugar $)$ \\
\hline Algodão empluma*** & $392\left(8^{\circ}\right.$ lugar $)$ & - \\
\hline Cana de açucar*** & $338.002\left(1^{\circ}\right.$ lugar $)$ & - \\
\hline Milho*** & $35.000\left(3^{\circ}\right.$ lugar $)$ & - \\
\hline
\end{tabular}

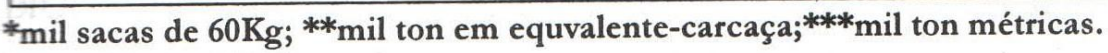

Fonte: Castro (2001). ções que os mercados futuros devem preencher é gerar um mecanismo para promoção dos preços futuros para as mercadorias, permitindo risco de oscilações de preços 
presentes ou futuros. Logo, a eficiência do mercado depende do número de participantes ativo, já que, sem volume de negócios que promovam a liquidez dos contratos nenhum mercado pode progredir.

O mesmo autor comenta que a intermediação das negociações entre compradores e vendedores no mercado futuro é representada por sociedades, corretoras engajadas na aceitação ou no repasse de ordens de compra ou de venda de uma mercadoria. Cabe as corretoras uma participação de grande responsabilidade e influência, por que a elas- muito mais que simplesmente intermediar operações (recebendo comissões por tais serviços) - competem a informação, o aconselhamento e a orientação dos clientes.

Atualmente, um contrato futuro é visto como um instrumento financeiro. Trata-se de uma troca de compromisso monetário por compromisso em mercadoria, de tal forma que aos especuladores cabem as obrigações financeiras e aos hedgers as obrigações que dizem respeito ao manuseio da mercadoria. A presença dos especuladores no mercado é economicamente benéfica, uma vez que fornece prontamente a liquidez necessária para absorver atividade de hedging (CHICAGO BOARD OF TRADE, 1985).

Uma medida de desempenho do mercado futuro é a sua liquidez. A liquidez é entendida como a possibilidade que tem todo e qualquer negociante, seja bedger ou especulador, de concretizar a sua operação tanto de compra como de venda de contratos. Assim, quanto maior a liquidez, menor o custo mínimo ao qual seja possível abrir uma posição e depois encerrála. Neste sentido, o mercado líquido permite a fácil realização da compra e da venda de contratos futuros, decorrente da presença de um grande número de compradores e vendedores, dispostos e capazes de negociar quantidades substanciais com pequenas diferenças de preços.

As diferenças entre hedgers e especuladores são muito mais teóricas do que empíricas. De fato, tanto o hedger quanto o especulador entram no mercado para conseguir lucros e assim fazendo ambos assumem riscos, portanto em última análise, os dois especulam (FORBES, 1986).

\subsection{Mercado Futuro e Físico}

De acordo com Souza (1994) o motivo fundamental pelo qual fazer hedger de posições fisicas com posições em futuros constitui um meio de proteção adequado, é o fato de que o preço à vista e o futuro tendem a se movimentar em harmonia um com o outro, mantendo, na maior parte das situações, um relacionamento essencialmente previsível. Esse movimento paralelo de preços manifesta-se porque tanto os mercados fisicos como os futuros são regidos e influenciados pelos mesmos fatores de composição e formação de preços.

Outra razão para o parentesco assim próximo entre os movimentos de preço à vista e futuros é o fato de a commodity física poder ser entregue contra o contrato futuro. Na prática, como já foi comentado, a entrega física ocorre em menos de $2 \%$ de todos os contratos futuros que são realizados. Apesar disso, a possibilidade de entrega da commodity física contra o contrato futuro garante a realidade da relação econômica entre preços á vista e a futuro. Quando inicia-se o mês de vencimento dos contratos futuros, os preços à vista e a futuro tendem a convergir. Se não o fizerem, quem estiver negociando em ambos os mercados poderá comprar naquele de preço mais baixo e vender no de preço mais elevado, sempre que as diferenças entre eles sejam suficientes para pagar os custos anualmente adicionados à entrega ou ao recebimento da commodity, contra contratos futuros. Isso faria com que ambos preços refletissem as verdadeiras oferta e procura existentes e mantivessem suas relações básicas. Assim, o nível de paralelismo entre oscilações de preços nos mercados à vista e futuro é que determina o grau de eficiência das operações de hedging (SOUZA, 1994).

Ainda que estas relações de preços entre mercados futuros e físicos não sejam exatamente harmônicaś, evidências empíricas sustentam coerência nessas variações. É muito raro o movimento de preços à vista e futuro assumirem direções opostas. Isto ocorre porque o bedger transfere para o especulador o risco das oscilações no preço absoluto e fica com o risco de variação da base.

O fenômeno de convergência da base no mês de vencimento do contrato futuro é de fundamental importância para o entendimento das estratégias de compra e venda de contratos futuros. Assumindo que os custos de carregamento da posição (armazenamento, juros e seguros) e taxas de transporte sejam considerados constantes, durante um determinado período de tempo, a porção da base local, que reflete os custos de carregamento da posição, varia com o tempo. Quanto maior o prazo para o vencimento do contrato, mais altos serão os custos de carregamento da posição.

\subsection{O governo e o mercado futuro}

Uma rápida avaliação da experiência intervencionista governamental no mecanismo de comercialização das safras brasileiras, permite detectar o controle de preços agrícolas, efetuado por uma política comercial que não contemplava as exportações e realizava importações subsidiadas (SOUZA, 1994).

Para reverter, em parte, essa tendência, a lógica do governo consistiu em 1994 justamente numa reforma do mecanismo de preços, onde o seu papel é liberar a comercialização de sua massiva interferência, levando os preços a refletirem a escassez e o custo de oportunidade dos produtos no mercado externo.

Uma ação governamental com o objetivo de estimular os mercados futuros esteve inserida no pacote agrícola do ano de 1992. Tratou-se da criação do fundo de commodities no mês de setembro daquele ano. Existe uma obrigação de que 10\%, no mínimo, do volume do fundo deverá ser contratado em operações de commodities agrícolas no mercado futuro. Em março de 1994, o valor patrimonial destes fundos girava em torno de 11 bilhões de dólares (BOLSA DE MERCADORIAS \&FUTUROS,1994). 
- A diminuição da interferência governamental no setor agrícola é positiva para o desenvolvimento dos mercados futuros no Brasil, na mesma medida que o governo, suas autarquias, agências e dependências estiverem a par, interessados e motivados para participar do mercado. Nesse sentido a participação do governo assume uma função primordial para o mercado de futuros. Quanto mais as autoridades institucionais estiverem informadas sobre a área, melhor; quanto mais a desconhecerem, tanto pior para a montagem e funcionamento do mercado.

De acordo com Nascimento (1998) dentre as vantagens oferecidas pelas negociações em bolsa está a de facultar ao governo um sistema de garantia de preços, com proteção em bolsa, o governo pode deixar de ser um eventual comprador, transferindo ao mercado essa função, liberando-se da negociação e dos riscos de perdas a ela inerente.

Criam-se condições de o governo planejar uma ação reguladora, atuar com mais segurança, manter quantidades mínimas de estoques físicos e maior de estoques papel, assegurando um abastecimento equilibrado ao longo do ano e transferindo ao mercado o ônus do custo burocrático e dos risco de armazenagem. Ele poderá realizar compras e vendas a preços mais representativos do mercado, protegendo-se contra variações bruscas de preços dos estoques.

Quando o governo reduz o seu papel de interventor nos mercados agrícolas, os mercados futuros constituem um instrumento de comercialização agrícola eficiente para os empresários rurais. Estes, ao negociarem contratos futuros em bolsa, estarão carregando seus estoques de safra para uma época mais favorável de venda que, naturalmente, é aquela mais distante da colheita. Por outro lado, em um ambiente turbulento em que o comportamento dos preços das commodities agrícolas, das taxas de juros e das taxas de câmbio continuam se mostrando altamente instáveis, revelam riscos elevados nessa situação inflacionária.

\section{O EMPRESÁRIO RURAL NO MERCADO FUTURO}

A crise do Estado brasileiro nos últimos anos agravada por uma política agrícola inconsistente e a transição políticoeconômica que o país atravessa determinam condições extremamente favoráveis ao desenvolvimento de um novo modelo em que o governo perde o papel de principal financiador da agricultura. Neste contexto, as condições de risco e incertezas na atividade são acentuadas, cabendo ao empresário rural considerar cada vez mais a utilização do gerenciamento destes riscos, através da participação da consecução de instrumentos que possam atenuá-los.

O empresário rural brasileiro tem um padrão educacional mais baixo, quando comparado com empresários dos outros setores da economia, o que dificulta o entendimento da terminologia das bolsas. A grande distância dos centros de decisão torna os empresários mais desconfiados da própria bolsa. Possuem a errônea concepção de que a bolsa estabelece o preço no pregão. Ressalta-se que a estacionalidade da produção agrícola faz com que as receitas do produtor não sejam diárias, acostumando-o a comercializar o produto físico. No mercado futuro a liquidez é continua, os ajustes são diários e raramente a liquidação dos contratos futuros se dá por entrega efetiva do produto (NEVES, 1990).

As cooperativas constituem o elo entre o pequeno empresário rural e as bolsas. Por isso, elas são vistas como um meio de acesso destes produtores ao mercado futuro. Desta forma, essas associações podem desempenhar o papel de potenciais concentradoras da maior parte desses negócios. Por outro lado, através de um quadro de funcionários especializados, ao gerir os contratos em bolsa em nome de seus cooperados, as cooperativas estariam facilitando não só o acesso do pequeno produtor ao financiamento do ajuste diário, como também administrando-o.

As agroindústrias atuam de forma indireta quando existe uma referência de preços para as negociações contratuais nas cadeias, uma vez que os preços das commodities nos mercados futuros tornam-se a referência obrigatória e são utilizados para a fixação dos preços correntes nas relações de trocas domésticas e internacionais. Os produtores e as agroindústrias, principalmente estas últimas, que assumem posições nos mercados futuros estão sempre ajustando suas ofertas de compra e venda de contratos, tendo por base o fluxo contínuo de informação sobre os mercados regionais e mundial (SOUZA, 1994).

As agroindústrias são constituídas de um número reduzido de empresas interdependentes, com grande concentração de mercado, constituindo-se em um oligopólio que utiliza-se de uma tecnologia avançada. Elas promovem barreiras à entrada pelo grande volume de capital requerido para investimento, bem como pelas relações conquistadas na cadeia. Possuem quadros profissionais de administradores que estão sempre atentos à dinâmica das oportunidades e ameaças externas, de forma que, ao assumirem posições nos mercados futuros, as cotações das commodities nas bolsas refletem em vantagem para o produtor, que ao firmar contratos com agroindústrias no mercado físico, esta últimas lhe confere uma diminuição dos riscos de preços.

As incertezas sobre os preços futuros constituem uma das principais fontes de instabilidade na produção. Os empresários rurais têm que tomar decisões entre alternativas de combinações de fatores, processo de produção e alternativa de expansão dos investimentos. É necessário aos empresários rurais o conhecimento dos mecanismos que conduzam a diminuição e ou redução dos riscos de preços, aperfeiçoamento de formação de expectativas e aumento da previsibilidade do comportamento do mercado agrícola.

Para o empresário rural, a rentabilidade implica em que a comercialização seja eficiente, o que significa melhorar o seu poder de barganha no mercado. Os mercados futuros estão intimamente relacionados com a administração dos riscos dos preços. Isto implica a possibilidade de redução dos riscos e a maximização dos retornos. Desta forma, estes serviços funcionam como instrumentos de cobertura e transferência de risco de mercado, com a vantagem de ser uma forma de 
privatização de transferência de riscos sem necessidade de participação do governo nesse processo.

\section{ESTUDOS EMPÍRICOS}

Mauger (1983) estudando o mercado futuro de café na Bolsa de Mercadorias de São Paulo observou que este mercado brasileiro tem um empresário rural que possui medo de vender a produção antes de tê-la, desconhecendo as vantagens, garantias e os riscos envolvidos nas operações. A liquidez da Bolsa era também muito reduzida, existindo relutância dos produtores rurais em aderir ao mercado de futuros.

O mesmo autor comenta que as grandes empresas preferem fazer bedging no exterior, uma vez que o mercado no Brasil é muito restrito. Os especuladores comparecem em número muito reduzido à Bolsa dẹvido a ausência da liquidez, atribui-se a ausência de especuladores e hedgers à falta de confiança na ampliação do volume de negócios e finalmente, a inflação e a excessiva interferência do governo na comercialização de produtos agrícolas.

Barros (1988) ao estudar as razões pelas quais os mercados futuros no Brasil não utiliza seu potencial, concluiu que os empresários que utilizam esses mercados no país, com fins de hedging, não conseguem reduzir seu risco por causa da forma pela qual a inflação afeta o fluxo de caixa dos seus ajustes diários. A demonstração foi feita com a commodity Índice de Ações IBOVESPA na Bolsa Mercantil \& de Futuros.

Alguns autores consideram que a principal dificuldade para o fortalecimento dos mercados futuros no Brasil é de caráter eminentemente político, dada a intensidade da intervenção governamental. Tofaneto (1989), em publicação da bolsa de mercadorias de São Paulo, argüi que não basta simplesmente que o governo manifeste o desejo de diminuir ou mesmo de eliminar o grau de interferência no processo de formação de preços. Esta tarefa requer a prática reiterada de medidas liberalizantes, onde deverão estar inseridas a regulamentação de operações cambiais, principalmente considerando a grande participação de empresas multinacionais no processo de comercialização.

Os mercados futuros, pelas suas características, parecem ser os mais próximos de um modelo de livre concorrência, onde predominam as leis de oferta e procura. No entanto, o mercado de futuros agrícolas no Brasil ainda não chegou ao seu pleno desenvolvimento, devido em parte, à forte interferência governamental na economia, através de controles de preços, choques econômicos e política intervencionista adotados, com e nem sempre claro, objetivo de conter a inflação, o que acaba por distorcer o mercado.

\section{CONSIDERAÇÕES FINAIS}

A negociação entre os investidores ocorrem de acordo com as leis de mercado e com o livre arbítrio dos mesmos em aceitar ou não a operação, já que podem ser diferentes as pre- visões de preço entre os investidores e o acesso rápido a informações decisórias. A bolsa garante segurança e liberdade para que investidores realizem as variadas transações que podem ser efetuadas pelos investidores. Ela é um importante canal de negociação da produção brasileira, já que as transações seriam mais dispersas e duvidosas sem esse tipo de negociação e sem uma forte instituição coordenando.

O empresário rural ainda é inseguro quanto ao mercado futuro, além deter uma tendência a ser bastante conservador, principalmente quando se fala de pequenos a médios empresários. Prefere, ainda, continuar com o mesmo tipo de comercialização que utilizava no passado, influenciado pelo receio à mudança. Espera ter o produto em mãos para depois procurar comprador, quando fica sabendo quanto vale o seu produto. Muitos produtores com sistema moderno e eficiente ainda são avessos a fazer proteção de preço.

Para o especulador as vantagens estão na possibilidade de transacionar diariamente e de conseguir lucros apenas por conhecer bem o mercado, estar bem informado, por analisar gráficos, séries históricas de preços, por ter tempo de acompanhar de perto os principais fatores econômicos e políticas que influenciam o mercado, para que assim consiga antecipar tendências. Permite ao produtor rural planejar sua atividade fazendo orçamentos com controle dos gastos. Vendendo a futuro o empresário rural pode se antecipar do valor da receita que irá receber e controlar melhor seus custos.

O mercado futuro oferece mais vantagens ainda do que a simples proteção de preço. O empresário rural pode, dentro dos prazos estabelecidos, sair a qualquer momento de sua posição, antes do término do contrato, recomprando sua posição e vendendo quando for interessante.

Através da tendência de mercado é possível estar atento as suas posições na BM\&F e de acordo com a cotação, podese comprar ou vender posições. Se vendeu a um determinado preço e alguns dias após a cotação para a de fechamento do seu contrato cair ele pode recomprá-lo se achar interessante, obtendo ganhos e deixando o mercado logo após e, se a cotação subir ele pode voltar a vender, sendo assim, comprador na baixa e vendedor na alta. Pode-se cercar até mesmo quando está tomando prejuízo.

Um dos fatores que mais restringem a participação dos empresários rurais no mercado futuro é que, por falta de tradição, de informação e medo, muitos deles tem receio de negociar na bolsa, achando que vão levar prejuízo.

A principal limitação que se observa neste mercado é a de ter gastos com os ajustes diários (variações de preços desfavoráveis estabelecidos pela $B M \& F$ e os custos operacionais que pode levar o bedger a desistir da operação.

O que poderia ser feito para tentar incentivar os empresários a negociarem na bolsa seria este, como entidade, fazer campanhas informativas mostrando aos empresários rurais o funcionamento, as vantagens, o modo operacional e divulgar mais o mercado aos que ainda não o conhecem. Deve-se estudar a possibilidade de abrir mais escritórios como consultoria no interior dos estados produtores, facilitando e assegurando o recebimento de ordens de compra e venda, aproximando-se 
assim dos empresários para gerar mais segurança e reduzir custos para os mesmos.

\section{REFERÊNCIAS BIBLIOGRÁFICAS}

ASSOCIAÇÃO BRASILEIRA DE AGROBUSSINESS. Segurança alimentar.uma abordagem de agrobusiness. São Paulo, 1993.

BARROS, V. P. Mercados futuros no Brasil: um estudo sobre inflação e bedging. Salvador: EA/UFBA, 1988. 123p. (Dissertação de mestrado em Administração de empresas).

BOLSA DE MERCADORIAS \& FUTUROS. Resenha. São Paulo, 1992-1994.

CASTRO, L. G. J. Mercados de derivativos agropecuários :Futuros, opções e CPR. Lavras: Universidade Federal de Lavras. 151p. 2001. (Apostila) CHICAGO BOARD OF TRADE. Commodity Trade Manual. Chicago, 141 p. 1985.

FORBES, L. F. Princípios básicos para aplicar nos mercados futuros. São Paulo: Bolsa Mercantil \& Futuros, 52 p. 1986.
MAUGER, P. Mercado futuro de café na bolsa de Mercadorias de São Paulo. Rio de Janeiro: COPPEAD, 110 p. 1983. (Dissertação de Mestrado em Administração de Empresas).

NASCIMENTO, D. A; Uma análise económica do mercado futuro de boi. São Paulo: PUC/SP 1998. (Monografia)

NEVES, M. E. A decolagem do mercado futuro de produtos agrícolas. Revista de Economia e Sociologia Rural. Brasilia, v. 28, n. 3, p. 11 18, jul./set. 1990

SOUZA, R.; ANDRADE, J. G. Administração Rural: um enfoque moderno. Informe Agropecuário. Belo Horizonte, v. 12, n. 173, nov. p. 3-5, 1986

SOUZA, W. A. O mercado futuro como instrumento de comercialização para o empresário rural. Lavras: ESAL, 90 p. 1994. (Dissertação de Mestrado em Administração)

TOFANETO, A. A função econômica dos mercados futuros. BOLSA DE MERCADORIAS \& FUTUROS. São Paulo: BMSP, 168 p. 1989.

TSUNECHIRO, A. o desempenbo dos mercados a termo: os casos do café, soja, e boi gordo na Bolsa de Mercadorias de São Paulo. São Paulo: FEA/USP, 124 p. 1983. (Dissertação de Mestrado em Economia) 